\title{
تطبيق طريقة بهوفيورال لكبار السن في حفظ أسماء الحسنى \\ (جمعة كار انغوني ، تاسيكمادو)
}

Uung Zuniatun Fathonah

Institut Agama Islam Negeri Surakarta

E-mail:fazuniatun06@gmail.com

DOI: $\underline{10.24252 / \mathrm{saa} . v 8 \mathrm{i} 2.12217}$

\begin{abstract}
Abstrak
Menghafal Asmaul Husna adalah hal yang dianggap mudah dikalangan masyarakat. Namun, setelah masyarakat mencoba untuk menghafal begitu banyak problematika yang muncul, salah satunya adalah kesulitan menghafal bagi masyarakat lansia atau yang telah lanjut usianya. Secara psikologis mereka sudah mengalami penurunan pada daya ingat mereka. Seperti yang dialami masyarakat Dusun Karangwuni, Desa Karangmojo, Tasikmadu, Karanganyar. Peneliti meneliti penerapan metode yang digunakan oleh lansia di Dusun Karangwuni supaya dapat belajar menghafal Asmaul Husna. Penelitian ini menggunakan metode kualitatif deskriptif dengan teknik analisis data observasi dan wawancara. Dengan hasil, bahwa metode behavioristik (metode yang diulang-ulang) cocok untuk menghafal di usia lanjut. Dan mempermudah untuk lansia belajar menghafal Asmaul Husna.
\end{abstract}

Kata kunci : Metod; Behavioristik; Asmaul Husna

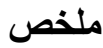

حفظ أسماء الحسنى هو شيء يعتبر سهل بين الناس. ومع ذلك، بعد أن يحاول المجتمع حفظ العديد من المشاكل التي تنشأ، و ون بينها صعوبة حفظ المسنين أو المسنين. فقد تقلصت من الناحية النفسية في ذاكرتهر. وكما هو الحال في قرية كارنغوني بكي

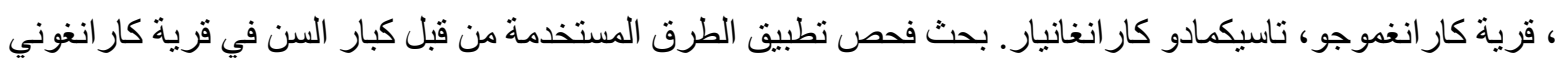

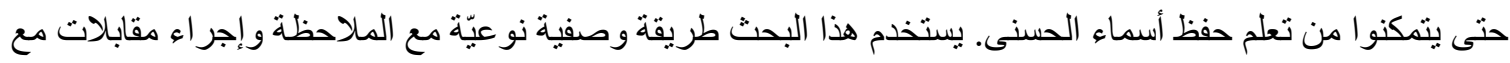
تقنيات تحليل البيانات. مع النتائج ، أن الطريقة السلوكية (الطريقة التي تتكرر ) مناسبة للحفظ في السن. ويسهّل على كبار السن تعلم حفظ المعلومات

الكلمة الأساسية: طريقة، سلوكية، أسماء الحسنى

المقدمة

الطريقة هي أهم شيء في التعلم. يعمل كوسيلة للطلاب لالتقاط ما نقله المعلم. ولكن، بالطبع، يتم تعديل الطريقة والمادة وفقاً لحالة الطالب. يجب أن يكون لكل معلم طريقته الخاصة للتعامل مع الطلاب الذين لم يتمكنو ا من التقاط ما تم تقديمه بشكل جيد. بالإضافة إلى 
ذللك، من المهم معرفة نفسية الطلاب. بالنسبة إلى الطلاب الذين لا يز الون صغار الأطفال بالطبع، يتطلب الأمر طريقة يعبّون بها مثيرة وممتعة. و على النقيض من الأطفال الذين هم في سن المراهقة بالفعل، فإن الطريقة المستخدمة معبأة معجبة بأنهم برون المعرفة في الو اقع. و على نحو ممانل، ننقل أمام كبار السن المهار ات المعرفية التي تتسم بها القدرة على اللحاق بالركب ليست بنفس السرعة التي تنقل بها المهارات الإدر اكية لدى الشباب. خاصة للتعرف على المشاكل مع الحروف العربية أو العربية. وبسبب حقيقة أن العديد من كبار السن الأميين من الهجرة، والعديد من كبار السن الذين لا يستطيعون قراءة القرآن، فمن الصعب تذكره بسبب العامل العمري حتى يكون دافعهم للتعلم منعدماً للغاية، فهم أقل منزلة من أن يتعلموا عن الأديان التي تذكروا / ذاكرة. ثم هنالك حاجة إلى الطريقة / الطريقة الصحيحة حتى يتمكنوا من تعلم القرآن والعلوم الأخرى. لذلك في هذه المناقثنة نناقش الطريقة السلوكية المستخدمة في قرية كار انغوني الفرعية، قرية كار انغموجو. هو تطبيق من هذا طرق يستطيع جعلت المسنات يستطيع استظهار أسماء الحسنى.

\section{طرق البحث}

الطريقة المستخدمة هي أسلوب المقابلة النوعية الوصفية حيث أن المصدر الرئيسي هو الأشخاص الذين يتبعون التلاوة في مسجد قرية كارنغوني.

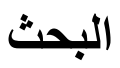

أ) تعريف الطريقة

ووفقا للقاموس الاندونيسي الكبير، فإن الطريقة هي طريقة منهجية للعمل على تيسير تنفيذ نشاط من أجل تحقيق الاهداف المحددة. الطريقة تأتي من الكلمة أسلوب (الإنكليزية) ، بمعنى من خلال ، تمرير ، طريق أو طريقة للحصول على شيء. الطريقة المستخدمة في هذه المناقشة هي الطريقة المستخدمة في عملية التعلم. يمكن تفسير التعلم على أنه أي جهد 
منهجي ومتعدد لتهيئة الظروف بحيث يمكن أن تعمل أنشطة التعلم بكفاءة وفعالية. لا تعمل طريقة التعلم كطريقة لتقديم المادة فحسب، لأن مصادر التعلم في أنشطة التعلم لها نطاق و اسع من المهام، بالإضافة إلى تقديم المعلومات، كما أن لها مهمة إدارة أنشطة التعلم بحيث يمكن أن يتعلم المو اطنون كيفية تحقيق أهداف التعلم الخاصة بهم بشكل مناسب. لذلك، يمكن تفسير طريقة التعلم على أنها طريقة تُستخدم لتنفيذ الخطط التي تم إعدادها في شكل أنشطة حقيقية و عملية لتحقيق أهداف التعلم. بناءً على ذلك، يكون لموضع الطريقة في التعلم نطاق

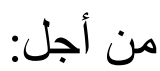

ا ـ التشيع، وهو الطريقة التي استخدمت بها موارد التعلم من أجل نشجيع تعلم المواطنين على الاستمر ار في التعلم r. الكثف عن تزايد الاهتمام بالتعلم، وهو وسيلة لتعزيز الحوافز من أجل زيادة الاهتمام بالتعلم لاى المو اطنين على أساس احتياجاتهم r. تقديم المو اد التعليمية، أي الطريقة التي تستخدمها مصادر التعلم لنقل المواد والأدوات في أنشطة التعلم

؛. خلق مناخ تعليمي مؤات، وهو طريقة لخلق جو تعليمي مبهج للطلاب ليتعلّمو ا فيه هـ القدرة على مولد الإبداع، وهو طريقة لتعزيز الإبداع في تعلم المواطنين وفقاً لإمكاناتهم 7 ـ دحركات التقويم الذاتي في العملية ونو اتج التعلم، وهي طرق لاكتشاف نجاح التعلم V. العو امل المحركة لإكمال نقاط الضعف في نو اتج التعلم، وطرق إيجاد حلول للمشاكل التي تمت مو اجهتها في أنشطة التعلم

لا تز ال استر اتيجية التعلم ذات طبيعة مفاهيمية لتنفيذها، يتم استخدام بعض طرائق التعلم. وبعبارة أخرى، فإن الاستر اتيجية هي "خطة عملية تحقق شيئا" في حين أن الطريقة هي "طريقة لتحقيق شيء ما" (وينا سيناجايا ، 1 . . ب). لذللك، يمكن تفسير طريقة التعلم على أنها وسيلة تُستخدم لتنفيذ الخطط التي تم إعدادها في شكل أنشطة حقيقية و عملية لتحقيق 
أهداف التعلم. هنالك العديد من طرق التعلم التي يمكن استخدامها لتنفيذ استر اتيجيات التعلم،

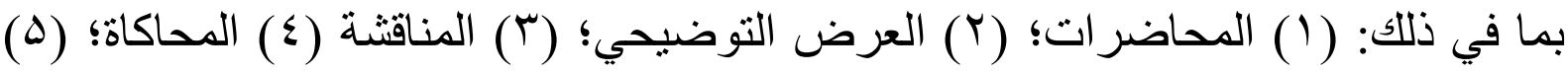

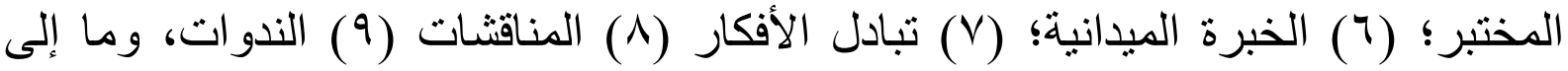

الطريقة السلوكية، أي طريقة الحفظ عن طريق التكرار في أغلب الأحيان إلى أن يتم حفظها عن طريق القلب (التعود). لذلك، تُمارس هذه الطريقة عادة كل يوم عن طريق الهتاف لتسهيل الحفظ.2

هذا الأسلوب يتماثنى مع النظرية السلوكية، وهي النظرية التي اقترحها جيج و برلينر حول تغيير السلوك نتيجة للخبرة. ثم تطورت هذه النظرية إلى تدفق من علم النفس التعليمي الذي أثر على اتجاه تطوير نظريات وممارسات التعليم والتعلم المعروفة بالتدفق السلوكي.

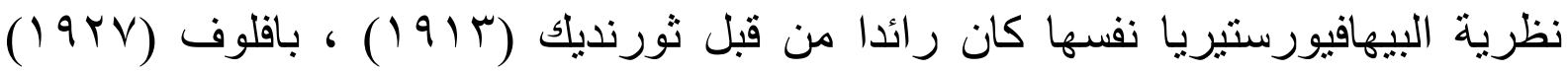
وسينر (9V\&) (198. تعتبر النظرية السلوكية أن التعلم هو سلوك يمكن ملاحظته بسبب المحفز ات الخارجية. و استناداً إلى هذا فإن هذه النظرية تفترض أن الثخص بمكن أن يُقال إنه يتعلم من السلوك الذي يمكن رؤيته، وليس من رأيه. توضح نظرية التعلم السلوكية أن التعلم هو تغير في السلوك يمكن ملاحظته وقياسه وتقويمه بشكل محسوس. يحدث التغيير من خلال المنشطات التي تسبب علاقات سلوكية تفاعلية (ردود) تستند إلى قو انين ميكانيكية. إن ردود ليس سوى بيئة تعلم الطفل، الداخلية والخارجية على حد سواء، التي هي سبب التعلم. و استناداً إلى هذا فإن هذه النظرية تفترض أن الثخص يمكن أن يُقال إنه يتعلم من السلوك الذي يمكن رؤيته، وليس من رأيه. توضح نظرية التعلم السلوكية أن التعلم هو تغير في السلوك يمكن ملاحظته وقياسه وتقويمه بشكل محسوس. يحدث التغيير من خلال المنشطات

\footnotetext{
${ }^{1}$ http://file.upi.edu/Direktori/FIP/JUR._PEND._LUAR_SEKOLAH/195404021980112001IHAT_HATIMAH/Pengertian_Pendekatan,_strategi,_metode,_teknik,_taktik_dan.pdf

${ }^{2}$ https://pendidikananakislam.blogspot.com/2008/08/metoda-baru-menghafal-asmaul-husna.html
} 
التي تسبب علاقات سلوكية تفاعلية (ردود) تستند إلى قوانين ميكانيكية. ولا يختلف المنبه عن بيئة التعلم الخاصة بالأطفال، الداخلية والخارجية على حد سواء، التي هي سبب التعلم. وفي حين أن الاستجابة هي نتيجة أو تأثثير، في شكل تفاعل معين مع المنشطات. يعني التعلم تعزيز الروابط والروابط وسمات السلوك والميول (التحفيز - الاستجابة). خصائص

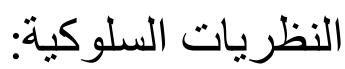

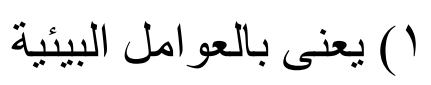
Y (التركيز على أجز اء العوامل r) التأكيد على السلوك المرئي باستخدام أساليب موضوعية. الطبيعة الميكانيكية ؛ ) فيما يتعلق بالماضي3 إن نظرية التعلم من خلال المذهب السلوكي لها تأثير كبير على عالم التعليم بحيث يتم توليد العديد من طرق التعلم من هذه النظرية. في ما يلي بعض الطرق التي تستند إلى هذه النظرية مثل طريقة الإقامة و العرض التوضيحي و المثقب و القر اعة بصوت عالٍ و النمذجة. 4 في طريقة السلوك سيقوم المعلم الذي يستخدم النموذج الفكري السلوكي بترتيب مادة الدرس الجاهزة بحيث يتم تسليم أهداف التعلم التي يتقنها الطلاب بالكامل من قبل المعلم. لا يلقي المعلم محاضر ات فحسب، بل يقدم أيضاً أمثلة. يتم ترتيب مادة الدرس في تسلسل هرمي من بسيط إلى معقد. يمكن قياس نتائج التعلم وملاحظتها، ويمكن تصحيح الأخطاء. و النتيجة المتوقعة هي تكوين سلوك مرغوب فيا.

\footnotetext{
${ }^{3}$ https://www.karyatulisku.com/2016/05/pengertian-teori-belajar-behaviorisme.html

${ }^{4}$ Moh. Roqib, ilmu pendidikan islam, (yogyakarta : PT LKS Printing Cemerlang, 2011) cet. I h.112
} 
هذه الطريقة مناسبة لاكتساب القدرات التي تتطلب الممارسة والتعود الذي يحتوي على عناصر السرعة التلقائية والقدرة على التحمل، الخ. وهذه النظرية مناسبة أيضا لتطبّق لتدريب الأطفال الذين لا يز الون بحاجة إلى دور الوالدين. يكمن ضعف هذه الطريقة في أن تعلم الطلاب المنمركز حول المعلم ميكانيكي وموجه نحو النتائج. ينظر إلى الطلاب على أنه سلبي، ويستمع الطلاب فقط، ويحفظ تفسير المعلم حتى يكون المعلم مركزياً واستبدادياً. في هذه النظرية، يركز المعلم بشكل أكبر على أهداف التعلم من دون إعطاء الأولوية للعملية بحيث يتم إعطاء الطلاب نظرية الممارسة المتكررة فقط دون معرفة ما إذا كانت عملية الطالب طبيعية أم لا.

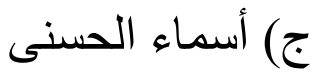
ومن حيث الهارفية، فإن معنى أسماء حسينية هو "أسماء طيبة". الربو يعني الأسماء. الحسنى تعني الخير. وتثير أسماء الحسنة إلى أسماء الله سبحانه وتعالى وعلمته و علمائه وخصائصه الجميلة. إن مصطلح أسماء الحسنى مذكور من قال الله سبحانه وتعالى في

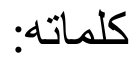

"Dialah Allah, tidak ada Tuhan (yang berhak disembah) melainkan Dia. Dia mempunyai asmaa'ul husna (nama-nama yang baik)"(Q.S. Thaha:8).

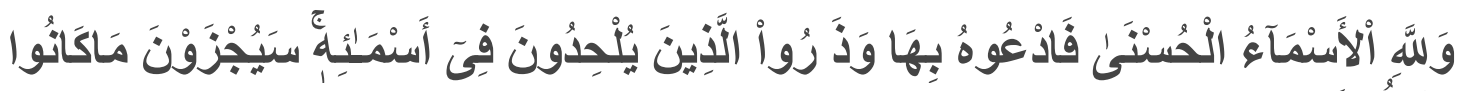
يَعْمَلُونَ

"Hanya milik Allah al-Asma-ul Husna (nama-nama yang agung yang sesuai dengan sifatsifat Allah), maka bermohonlah kepada-Nya dengan menyebut nama-nama baik itu, dan tinggalkanlah orang-orang yang menyimpang dari kebenaran dalam (menyebut) namanamaNya. Nanti mereka akan mendapat balasan terhadap apa yang telah mereka kerjakan."(QS. Al-A'raf: 180) makalah/

${ }^{5}$ https://kamalfachri.wordpress.com/2009/01/19/kepribadian-guru-penentu-masa-depan-pendidikan-

${ }^{6}$ https://www.jatikom.com/2019/10/asmaulhusna-pengertiantujuanmanfaatdalilartigambar.html 


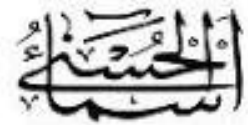

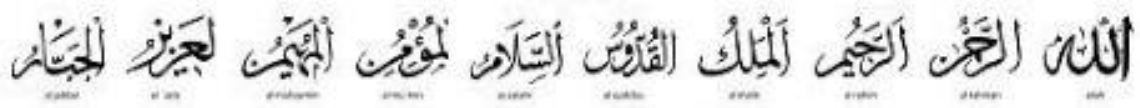

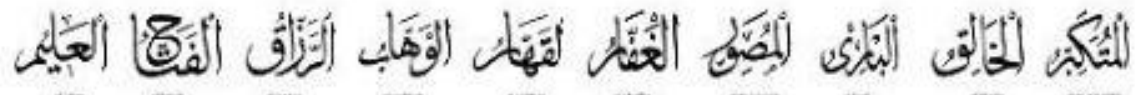
管

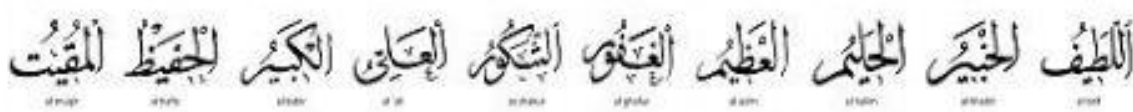
型 期

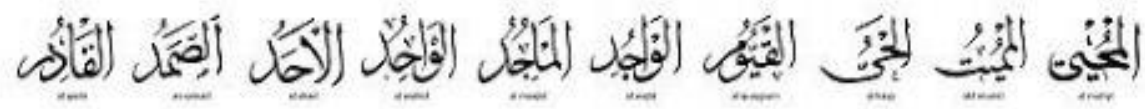

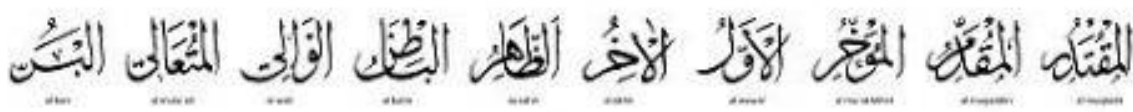
到

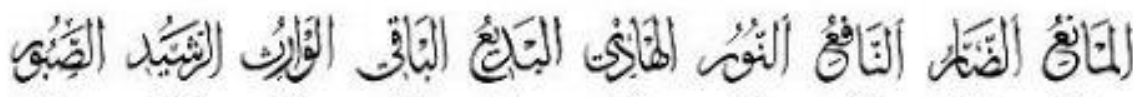

الكار انغوني هامليت هي إحدى القرى في كار انغموجو، تاسيمادو، كار انغانيار . هناك حجاج يتجمّعون بعد صلاة المساء حتّى المساء. الروتين اليومي يقومون بذلك. الأمهات اللواتي دخلن سن • ع سنة أو أكثر يتعلمن أن يستفيدو ا من أسمول هوسنا معا بتوجيه من إيبو روحمادي. لا يمكن أن يكون هناك أي شيء آخر في هذا المجال. يكرر كل شخص ما يصل إلى V مر ات، ثم يحفظ معًا ويتكرر V مر ات بعد ذللك من البداية إلى آخر كلمة يتم حفظها في الذاكرة لمدة V مرات أيضًا. وما إلى ذللك حتى شعر الحجاج بأنهم حفظوا في حفظهم. ثم 
طلبت والدة روحمادي من أحد من الجماعة حفظ كلمة أسمول هوسنا في الذاكرة من البداية. أما الجماعة الأخرى فقد استمعت إليها.

إذا كان هنالك خطأ في نطق الأم روحمادي يصحح. وبعد ذلك يتم غنيها معاً في نغمة يسهل حفظها بالذاكرة. قبل الختام، عادة ما تعطي والدة روحمادي الحافز للطائفة للحفاظ على حماسها في تعلم حفظ أسمول هوسنا حتى و إن لم تكن قوية في العمر والطاقة عندما كانوا صغار السن. ومع ذللك، على الرغم من أنه كان يسير بسلاسة هناك عقبات لأن هناك المزيد والمزيد من التجمعات، وفي بعض الأحيان هناك أمهات بطلبن تكرار ما تم تعلمه في الاجتماع أمس. ولكن و الدة روحمادي طوبت ببر اعة، كانت دائما غائبة قبل أن تبدأ الدارس وتتذكر ما تعلمناه في الاجتماع أمس.

وفي ظل هذه الظروف، فإن طريقة التعلم التي تستخدمها أم روحمادي هي طريقة سلوكية، أي تكرار، إعطاء حافز للتجمع حتى تتمكن الجماعة من جعل الحفظ عادة سهلة. جعل تعلم حفظ أسمول هوسنا أكثر إثارة ، وسهولة أن نتذكر. هكذا مع أنّ ، هذا طريقة

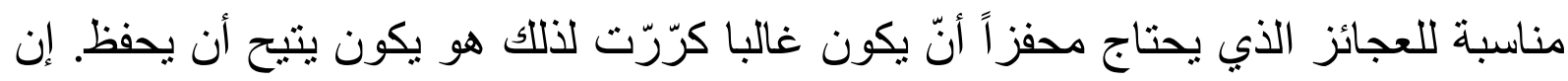

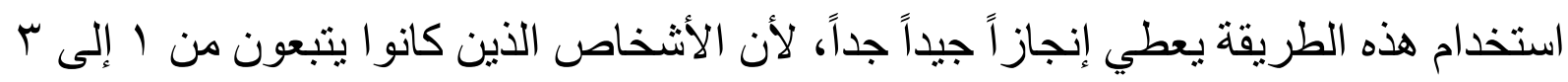
أنخاص فقط كانوا في السابق يستطيعون اتباعه. ومن ناحية أخرى، وبعد استخدام هذه

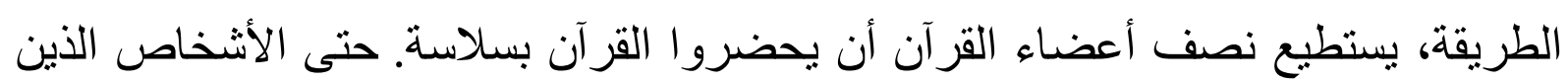
شاركوا لأول مرة في هذه التلاوة كان بوسعهم أن يتذكروا على الفور ما حفظوه.

\section{الاستنتاجات}

طريقة بيهافيورستيتش هي طريقة تستخدم في حفظ ، عن طريق تكرارها حتى يتم حفظها عن طريق القلب. أساليب التعلم من خلال تغيير السلوك. مناسب للتعلم الذي يتطلب مهار ات عملية وسكن. مناسب لتذكير أسمول حسينية أو القرآن. ومع ذللك، فإن هذه الطريقة لها نقاط ضعف، بما في ذلك: تتطلب المزيد من الوقت و الطاقة و الأفكار، و لا تذكر إلا تسلسلات الكلمات (متسلسلة) وهي منطقية / نسبية، تعتمد على عمل 
الدماغ الأيسر الذي هو ذاكرة قصيرة المدى (ذاكرة قصيرة المدى) الذي يستطيع فقط متأخّرة

T ساعات ، النتيجات متتوعت لأنّ التركيز قوة من كلّ شخص يكون مختلفة ، التنفيذ / ممارسة من القيم [ولدسّ] يحتوي في [اسماء] حسنى] يفتقر لأنّ هو لا يعرف معناه. مراجع

Hatimah. URL

http://file.upi.edu/Direktori/FIP/JUR. PEND. LUAR SEKOLAH/1954040219801120 01IHAT_HATIMAH/Pengertian_Pendekatan,_strategi,_metode,_teknik,_taktik_dan.p df. HTML. (online, 23 Desember 2019)

Fianda. URL https://pendidikananakislam.blogspot.com/2008/08/metoda-baru-menghafalasmaul-husna.html. HTML. (online, 23 Desember 2019)

https://www.karyatulisku.com/2016/05/pengertian-teori-belajar-behaviorisme.html HTML. (online, 23 Desember 2019)

Moh. Roqib, Ilmu Pendidikan Islam, Yogyakarta : PT LKS Printing Cemerlang, Cet I. 2011

https://kamalfachri.wordpress.com/2009/01/19/kepribadian-guru-penentu-masa-depanpendidikan-makalah/ HTML. (online, 23 Desember 2019)

https://www.jatikom.com/2019/10/asmaulhusnapengertiantujuanmanfaatdalilartigambar.htm 1 HTML. (online, 23 Desember 2019) 